\title{
Sodium handling in patients with well compensated cirrhosis is dependent on the severity of liver disease and portal pressure
}

\author{
R Jalan, P C Hayes
}

\begin{abstract}
Background and aims-To test the contribution of portal pressure gradient (PPG) and neurohumoral factors to sodium handling in cirrhotic patients without ascites, by comparing preascitic cirrhotic patients with patients with transjugular intrahepatic portosystemic stent shunt (TIPSS) and previous ascites.

Patients-Ten patients with TIPSS and 10 preascitic cirrhotic patients.

Methods-Changes in glomerular filtration, renal plasma flow, urinary sodium excretion $\left(U_{\mathrm{Na}} V\right)$, and neurohumoral factors were measured before and for two hours after infusion of one litre of $0.9 \%$ saline over one hour.

Results-Glomerular filtration rate and renal plasma flow were significantly higher in patients with TIPSS compared with preascitic cirrhotic patients. Following saline infusion both parameters increased significantly; this increase was significantly greater in patients with TIPSS. $U_{\mathrm{Na}} \mathrm{V}$ increased significantly in both groups following saline infusion. The increase in $\mathrm{U}_{\mathrm{Na}} \mathrm{V}$ was significantly greater in the TIPSS group. Plasma renin activity and angiotensin II decreased significantly in both groups. Basal $\mathrm{U}_{\mathrm{Na}} \mathrm{V}$ was independently correlated with angiotensin II concentration and PPG and the change in $\mathrm{U}_{\mathrm{Na}} \mathrm{V}$ correlated with the PPG.

Conclusions-Results suggest that patients with advanced liver disease and low portal pressure handle sodium as well as patients with compensated liver disease and high portal pressure. These results are consistent with the notion that in addition to peripheral vasodilatation and severity of liver disease, the severity of portal hypertension contributes to the abnormalities of sodium retention in cirrhosis.

(Gut 2000;46:527-533)
\end{abstract}

Liver Unit,

Department of

Medicine and Centre

for Liver and Digestive

Diseases, Lauriston

Place, Edinburgh, UK

R Jalan

P C Hayes

Correspondence to:

Dr R Jalan

Accepted for publication 22 October 1999

Keywords: cirrhosis; transjugular intrahepatic portosystemic stent shunt; TIPSS; angiotensin; sodium handling; peripheral vasodilatation

Liver cirrhosis is characterised by hyperdynamic circulatory changes including high cardiac output and decreased peripheral vascular resistance. ${ }^{1-3}$ These changes worsen with disease progression. ${ }^{4}$ Compensatory activation of the renin-angiotensin, ${ }^{5-10}$ sympathetic, ${ }^{11-13}$ and vasopressin ${ }^{14-17}$ systems contributes to the maintenance of vascular tone in these patients. The mechanism of retention of sodium in cirrhosis is unclear. Although several theories regarding the initiation of sodium retention in cirrhosis have been proposed, ${ }^{18} 19$ the most popular is the peripheral vasodilatation hypothesis which proposes that splanchnic hyperaemia and portal hypertension is the result of accumulation of splanchnic vasodilators because of reduced hepatic clearance and portosystemic shunting. This causes relative underfilling of the vascular compartment, which reduces effective arterial blood volume and stimulates release of neurohumoral factors in an attempt to restore vascular tone; retention of sodium and water returns the effective arterial blood volume to normal. ${ }^{20}$

Transjugular intrahepatic portosystemic stent shunt (TIPSS) successfully reduces portal pressure and is a useful treatment for ascites. Clearance of ascites occurs following TIPSS insertion despite advanced liver function. The improvement in ascites is thought to result from deactivation of the neurohumoral system with reduction in circulating renin, aldosterone, and angiotensin II (ANGII), and increased cardiac output. ${ }^{21-24}$ Expansion of the effective arterial blood volume with saline infusion in preascitic cirrhotic patients has shown abnormalities in renal circulation and tubular sodium handling before a decrease in the effective arterial blood volume. This abnormality is closely related to the severity of underlying liver disease. ${ }^{25} \mathrm{~A}$ confounding variable that these studies do not address is the role of concomitant portal hypertension; the relative contributions of increased portal pressure and the degree of liver dysfunction in producing defects of sodium handling in patients with liver disease are unclear.

Therefore, the aim of this study was to examine whether patients with severe liver disease and low portal pressure handle sodium as well as patients with mild liver disease and high portal pressure when subjected to acute saline loading. This study was performed in patients who were previously ascitic but had no ascites
Abbreviations used in this paper: ANGII, angiotensin II; ANP, atrial natriuretic peptide; cGMP, cyclic guanosine monophosphate; $\mathrm{Cl}_{\mathrm{Na}}$, sodium clearance; ET-1, endothelin 1; $\mathrm{FE}_{\mathrm{Na}}$, fractional excretion of sodium; $\mathrm{FL}_{\mathrm{Na}}$, filtered load of sodium; GFR, glomerular filtration rate; NA, noradrenaline (norepinephrine); PAH, $p$-aminohippuric acid; PPG, portal pressure gradient; PRA, plasma renin activity; $\mathrm{RPF}$, renal plasma flow; TIPSS, transjugular intrahepatic portosystemic stent shunt; $\mathrm{U}_{\mathrm{Na}} \mathrm{V}$, urinary sodium excretion. 
Table 1 Patient characteristics

\begin{tabular}{|c|c|c|}
\hline & $\operatorname{TIPSS}(n=10)$ & $\begin{array}{l}\text { Preascitic cirrhotics } \\
(n=10)\end{array}$ \\
\hline Age $(y)$ & $52.2(3.1)$ & $48.2(3.1)$ \\
\hline $\operatorname{Sex}(M / F)$ & $6 / 4$ & $4 / 6$ \\
\hline \multicolumn{3}{|l|}{ Aetiology of liver disease } \\
\hline Alcoholic cirrhosis & 6 & 5 \\
\hline Primary biliary cirrhosis & 3 & 3 \\
\hline $\mathrm{HCV} / \mathrm{HBV}$ & 1 & $1 / 1$ \\
\hline \multicolumn{3}{|l|}{ Child class } \\
\hline Class A & 5 & 8 \\
\hline Class B & 4 & 2 \\
\hline Class C & 1 & 0 \\
\hline Pugh score & $7.3(1.1)$ & $5.6(0.4)^{\star}$ \\
\hline \multicolumn{3}{|l|}{ Portal haemodynamics } \\
\hline Portal pressure $(\mathrm{mm} \mathrm{Hg})$ & $16.7(0.8)$ & \\
\hline Wedged hepatic venous pressure & & $20.1(0.5)^{\star}$ \\
\hline Inferior vena cava pressure & $8.6(0.6)$ & $4.1(0.5) \dagger$ \\
\hline PPG/HVPG & $8.1(0.8)$ & $16(0.6) \dagger$ \\
\hline Bilirubin $(\mu \mathrm{mol} / \mathrm{l})$ & $41.2(6.4)$ & $21.1(2.1) \ddagger$ \\
\hline Albumin $(g / 1)$ & $31.2(2.1)$ & $38.1(3.6) \dagger$ \\
\hline Prothrombin time $(\mathrm{s}) \mathrm{s}$ & $16.1(3.4)$ & $13.2(2.9)^{\star}$ \\
\hline Time from TIPSS (mth)/time from first variceal bleed & $3.6(1.4)$ & $4.5(1.1)$ \\
\hline Heart rate (beats per min) & $76(4.3)$ & $84(5.1)$ \\
\hline Mean arterial pressure $(\mathrm{mm} \mathrm{Hg})$ & $108.2(5.1)$ & $112.5(4.3)$ \\
\hline Cardiac index $\left(1 / \mathrm{min} / \mathrm{m}^{2}\right)$ & $5.1(0.9)$ & $3.7(0.5)^{\star}$ \\
\hline Systemic resistive index $\left(\mathrm{mm} \mathrm{Hg} / 1 / \mathrm{min} / \mathrm{m}^{2}\right)$ & $19.1(2.3)$ & $27.0(2.5)^{\star}$ \\
\hline
\end{tabular}

Results expressed as mean (SEM).

PPG, portal pressure gradient; HVPG, hepatic venous pressure gradient; $\mathrm{HCV}$, hepatitis $\mathrm{C}$ virus; HBV, hepatitis B virus.

${ }^{\star} \mathrm{p}<0.01,+\mathrm{p}<0.001, \neq \mathrm{p}<0.0001$

\Control, $12 \mathrm{~s}$

following insertion of TIPSS, and in patients who had early cirrhosis and established portal hypertension but no ascites. Changes in renal function and neurohumoral factors were determined in the basal state and also after acute saline loading.

\section{Methods}

SUBJECTS

Studies were undertaken with the approval of the local research ethics committee and in accordance with the Declaration of Helsinki (1989) of the World Medical Association and after obtaining written informed consent from each subject. Patients in both groups were included if they had biopsy proven cirrhosis. Patients with alcoholic liver disease abstained from alcohol for at least one month prior to the study. Patients were excluded if they had ascites (demonstrable on ultrasonography examination), pitting peripheral oedema, hepatic encephalopathy, clinically evident cardiovascular disease, renal dysfunction (decreased renal size on ultrasonography, proteinuria, or creatinine greater than $100 \mu \mathrm{mol} / \mathrm{l})$, or were receiving any diuretics or vasoactive medications. Patients

\section{Start infusion}

$\mathrm{PAH}$ and inulin infusion

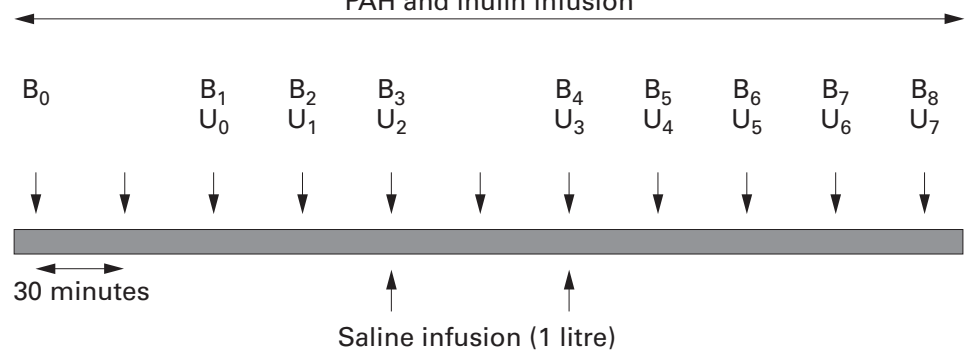

Figure 1 Study design. $U_{l}-U_{7}$, samples for urine volume, $p$-aminohippuric acid $(\mathrm{PAH})$, inulin, sodium, and creatinine; $B_{1}-B_{7}$, blood samples for $P A H$, inulin, sodium, and creatinine; $B, B_{4}$ and $B_{3}$, blood samples for plasma renin activity, angiotensin II, atrial natriuretic peptide, cyclic GMP, endothelin 1, and noradrenaline (norepinephrine). $B_{0}, B_{7}$ $B_{3}, B_{4}$ and $B_{6}, 250 \mathrm{ml}$ water orally to ensure adequate urine flow. were maintained on a diet with restriction of sodium intake to $150 \mathrm{mmol}$ per day for one week prior to the study.

Two groups of patients were studied (table 1). Group $1 \quad(n=10)$ comprised stable, preascitic cirrhotic patients with established portal hypertension who had bled from oesophageal varices a mean of 4.5 (1.1) months previously and were managed by variceal band ligation. Group $2(n=10)$ comprised patients who had undergone a TIPSS for bleeding from oesophageal varices and had ascites at the time of TIPSS insertion. They were included in the study if they had a portal pressure gradient of less than $12 \mathrm{~mm} \mathrm{Hg}$. Mean time from insertion of TIPSS to the study was 3.6 (1.4) months.

\section{STUDY DESIGN}

Patients were studied after an overnight fast between 8 am and $1 \mathrm{pm}$. Patients maintained a supine posture throughout the study, adopting the erect posture for voiding. Prior to the study, two venous cannulae were inserted, one in each arm (one for infusions and the other for sampling). Cardiovascular monitoring, which included measurement of blood pressure (Dynamap, Critikon, Australia) and pulse was performed at half hour intervals throughout the study. A primed, continuous infusion of ${ }^{3} \mathrm{H}$-inulin and $p$-aminohippuric acid $(\mathrm{PAH})$ was started as indicated and continued throughout the study. After two hours of PAH and inulin infusion, one litre of $0.9 \%$ sodium chloride was infused over a one hour period. Figure 1 shows the timing of the infusions and various samples during the study.

MEASUREMENT OF PORTAL PRESSURE

In the TIPSS group, portal pressure gradient (portal pressure - inferior vena caval pressure) was determined the day after the study at routine portography. Hepatic venous pressure gradient (wedged hepatic venous pressure inferior vena caval pressure) was measured in the patients in group 2 on the day after the study.

\section{MEASUREMENTS}

Blood (40 ml) was collected from a peripheral vein into precooled tubes. Plasma was separated and the samples stored at $-70^{\circ} \mathrm{C}$ for analysis at a later date. Blood was also sampled from a peripheral vein in 10 healthy volunteers with a mean age of 49.6 (2.4) years (seven men and three women) for the measurement of neurohumoral factors.

Routine biochemistry

Plasma and urinary concentrations of sodium were measured using standard automated systems.

\section{Measurement of glomerular filtration rate and} estimated renal plasma flow

Glomerular filtration rate (GFR) and estimated renal plasma flow (ERPF) were determined during a constant infusion of ${ }^{3} \mathrm{H}$-inulin (Amersham, International) and PAH (Merck, Sharpe and Dohme, Sydney, Australia) as 
described previously, and expressed per 1.73 $\mathrm{m}^{2}$ body surface area. Inulin concentration was measured using spectrophotometry, and PAH using high performance liquid chromatography. ${ }^{26}$

\section{Measurement of plasma renin activity}

The radioimmunoassay for measurement of plasma renin activity (PRA) was based on the principle that angiotensin I is generated by the action of renin on its substrate angiotensinogen. An in house antibody for angiotensin I was used. The coefficient of variation for the assay was $5.2 \%$. The reference range for PRA was $1.6(1.5) \mathrm{ng} / \mathrm{ml} / \mathrm{h}^{.6}$

Measurement of angiotensin II

Samples of blood were obtained in ANGII inhibitor. ANGII values were measured by radioimmunoassay with an in house rabbit antibody R6B4. The coefficient of variation for the assay was $3.2 \%$. The reference range for ANGII was $3.2(1) \mathrm{fmol} / \mathrm{ml}^{26}$

Measurement of atrial natriuretic peptide

The radioimmunoassay was performed using an antibody to human atrial natriuretic peptide (ANP) that had been raised in the rabbit following immunisations with human ANP. The coefficient of variation for the assay was $9.8 \%$. The reference range for ANP was 62.1 (7.1) $\mathrm{pg} / \mathrm{ml} .^{26}$

\section{Measurement of cGMP}

The dried samples were acetylated and plasma cGMP measured with an in house antibody (ED2-3). The coefficient of variation for the assay was $3.6 \%$. The reference range of cGMP was $1.18(0.34) \mathrm{nmol} / 1{ }^{26}$

\section{Measurement of noradrenaline}

Noradrenaline (NA; norepinephrine) was measured by an electrochemical method after separation by reverse phase high performance liquid chromatography. The coefficient of variation for the assay was $4.5 \%$. The reference range of NA was $1.3(0.34) \mathrm{pmol} / \mathrm{ml}^{26}$

\section{Measurement of endothelin 1}

Following extraction using Bond Elut columns, endothelin 1 (ET-1) concentration was determined using a radioimmunoassay as described previously. ${ }^{27}$ The coefficient of variation for the assay was $5 \%$. The reference range of ET-1 was 6.9 (1) fmol/1.

\section{MEASUREMENT OF CARDIOVASCULAR}

HAEMODYNAMICS

On the morning of the study, haemodynamic parameters including heart rate, mean arterial pressure, stroke volume, and cardiac output were measured using a non-invasive bioimpedance method (BoMed NC-COM3, BoMed Medical manufacturer Ltd); the systemic vascular resistance and cardiac index were calculated using standard formulae.

CALCULATIONS

Using the inulin clearance as a marker of glomerular filtration rate (GFR), and $\mathrm{PAH}$ clearance as a marker of renal plasma flow, urinary sodium, and urinary volume, the following parameters were derived using the formulae as follows: urinary sodium excretion $\left(\mathrm{U}_{\mathrm{Na}} \mathrm{V}\right.$, $\mathrm{mmol} / \mathrm{min}$ ): urinary sodium $\times$ urinary $\mathrm{vol} / \mathrm{min}$; filtered sodium load $\left(\mathrm{FL}_{\mathrm{Na}}, \mathrm{mmol} / \mathrm{min}\right)$ : $\mathrm{GFR} \times$ serum sodium; fractional excretion of sodium $\left(\mathrm{FE}_{\mathrm{Na}}, \%\right):\left(\mathrm{U}_{\mathrm{Na}} \mathrm{V} / \mathrm{FL}_{\mathrm{Na}}\right) 100$; sodium clearance $\left(\mathrm{Cl}_{\mathrm{Na}}, \mathrm{ml} / \mathrm{min}\right): \mathrm{U}_{\mathrm{Na}} \mathrm{V} /$ plasma sodium.

DATA ANALYSIS

All results were expressed as mean (SEM). Repeated measures analysis of variance (ANOVA) was used to compare data within the same group and the unpaired $t$ test was used to compare the difference between the two patient groups. Linear regression was used to test associations between renal, neurohumoral, and hepatic function parameters. Variables that reached statistical significance on the above analysis were entered into a multivariate analysis by stepwise logistic regression analysis.

\section{Results}

PATIENTS

The patients in both groups were well matched for age, sex, aetiology of liver disease, and duration since their first bleed. Patients in the TIPSS group had significantly more severe liver disease, manifested by lower albumin $(\mathrm{p}<0.001)$ and greater prothrombin time $(<0.01)$, bilirubin $(\mathrm{p}<0.0001)$, and Pugh score $(p<0.01)$. All the patients recruited into the study had normally functioning TIPSS and therefore a significantly lower portal pressure gradient $(p<0.01)$. Mean arterial pressure and heart rate were not significantly different between the groups but the inferior vena caval pressure was significantly higher in the TIPSS group. Cardiac index was significantly higher $(p<0.01)$ and the systemic vascular resistive index $(\mathrm{p}<0.01)$ was significantly lower in the TIPSS group. There was no significant change in heart rate or mean arterial pressure in either group following saline infusion.

RENAL HAEMODYNAMICS

Patients with TIPSS had significantly higher GFR (as measured by inulin clearance) and ERPF (as measured by PAH clearance) compared with preascitic cirrhotic patients $(p<0.05)$. Following saline infusion both GFR and ERPF increased significantly (figs 2 and 3). Basal $\mathrm{U}_{\mathrm{Na}} \mathrm{V}, \mathrm{FE}_{\mathrm{Na}}$, and $\mathrm{Cl}_{\mathrm{Na}}$ were similar in both groups but the filtered load of sodium was significantly greater in the TIPSS group. There was a significant increase in urinary sodium excretion (fig 4), fractional excretion of sodium, and sodium clearance in both patient groups. $\mathrm{U}_{\mathrm{Na}} \mathrm{V}$ was significantly greater in patients in the TIPSS group, one hour after saline infusion.

\section{NEUROHUMORAL FACTORS}

Table 2 summarises the changes in neurohumoral factors. PRA was significantly higher in both patient groups compared with healthy controls ( $p<0.05$ for both groups). There was a significant reduction in PRA after acute saline loading in both groups $(\mathrm{p}<0.01)$. This reduc- 


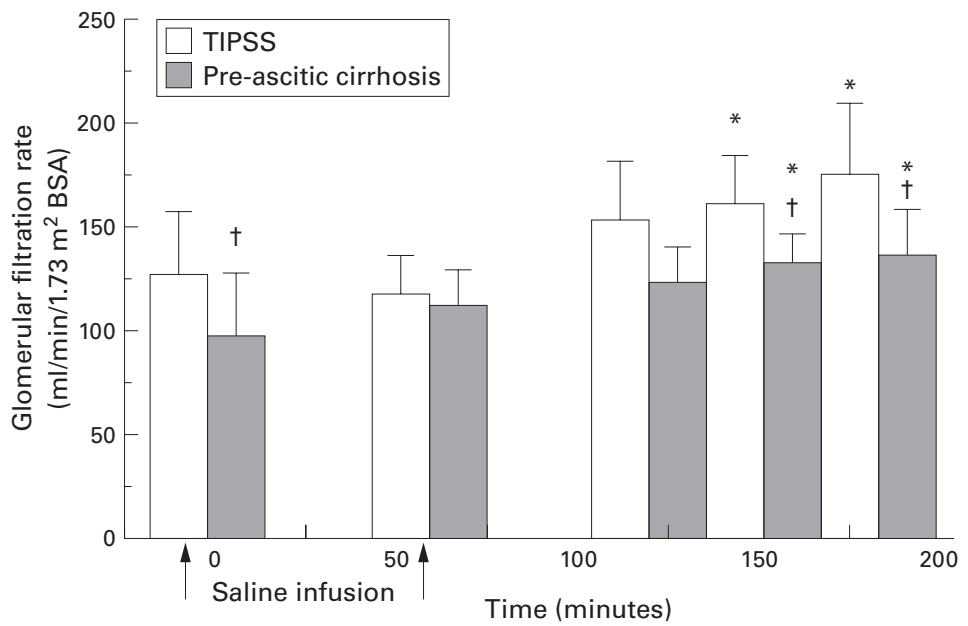

Figure 2 Changes in glomerular filtration rate following saline infusion. ${ }^{\star} p<0.05$ versus baseline; $t p<0.05$ between groups.

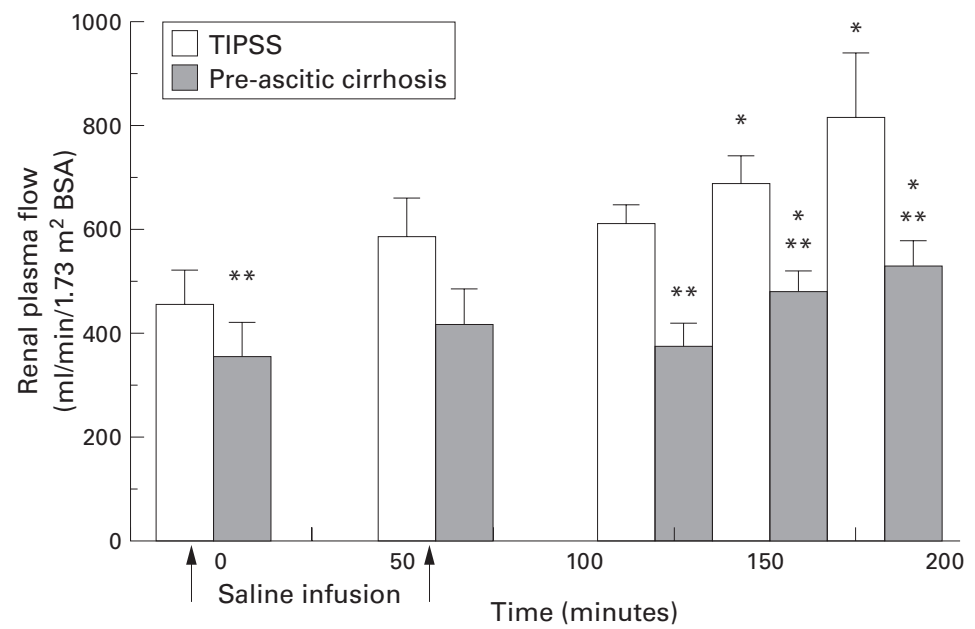

Figure 3 Changes in renal plasma flow following saline infusion. ${ }^{*} p<0.05$ versus baseline; $\star \star p<0.01$ between groups.

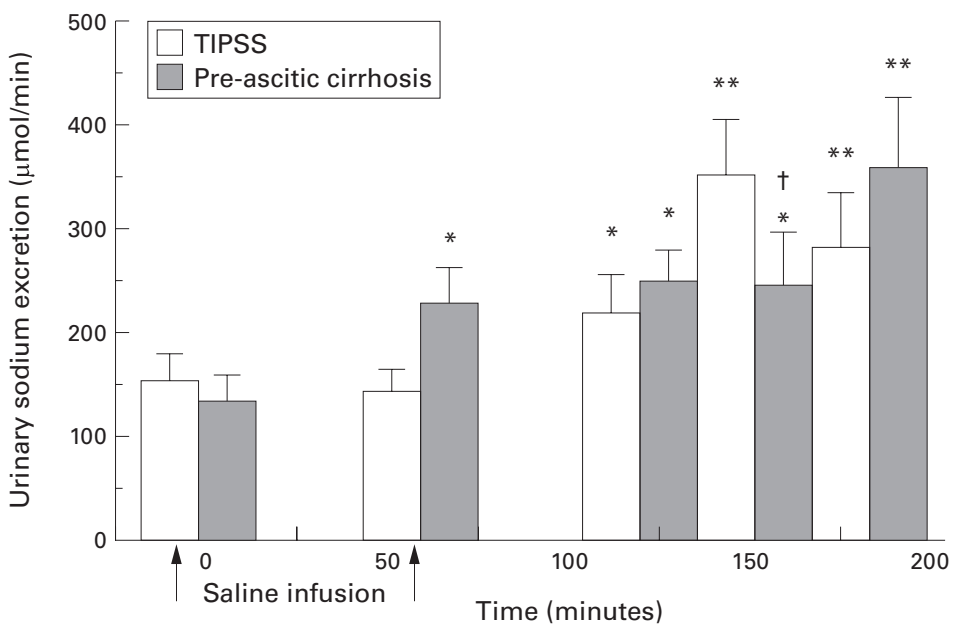

Figure 4 Changes in urinary sodium excretion following saline infusion. ${ }^{\star} p<0.05$, $\star \star p<0.01$ versus baseline; $t p<0.03$ between groups.

tion was not significantly different between groups. ANGII was significantly higher in the preascitic patients compared with healthy controls $(\mathrm{p}<0.05)$ and also compared with patients in the TIPSS group. There was no significant difference in ANGII between TIPSS patients and healthy volunteers. ANGII decreased significantly after saline infusion in both groups. ANP concentration was not significantly different between either group and healthy volunteers. There was no significant difference between the patient groups at baseline. There was a significantly greater increase in ANP after saline infusion in the TIPSS group. Cyclic GMP concentration was significantly higher in both patient groups compared with controls. There was no significant difference between groups and no significant change after saline infusion. Noradrenaline concentration was similar in both patient groups and controls and did not change significantly after saline infusion. ET-1 concentration was significantly higher in TIPSS groups compared with controls. ET-1 concentration was not significantly different between preascitic cirrhotic patients and healthy volunteers. ET-1 concentration was higher in patients in the TIPSS group but did not change significantly after saline infusion.

\section{RELATION BETWEEN VARIABLES}

Basal $\mathrm{U}_{\mathrm{Na}} \mathrm{V}$ correlated significantly with ANGII $(r=-0.78, \mathrm{p}<0.001)$, PRA $(r=-0.6, \mathrm{p}<0.001)$, and the portal pressure gradient $(r=-0.6$, $\mathrm{p}<0.001)$. Both ANGII and portal pressure gradient retained an independent relation with basal $\mathrm{U}_{\mathrm{Na}} \mathrm{V}(r=-0.54, \mathrm{p}<0.01$; and $r=-0.57$, $\mathrm{p}<0.01$ respectively). No significant correlation was detected between basal $\mathrm{U}_{\mathrm{Na}} \mathrm{V}$ and noradrenaline, ANP, cGMP, ET-1 concentration, and Pugh score, albumin, bilirubin, or prothrombin time. No significant correlation was detected between the change in $\mathrm{U}_{\mathrm{Na}} \mathrm{V}$ and the change in any of the measured neurohumoral factors. The change in $\mathrm{U}_{\mathrm{Na}} \mathrm{V}$ correlated significantly with the portal pressure gradient $(r=-0.55, \mathrm{p}<0.01)$ on univariate analysis. No significant correlation was detected between GFR and ERPF, and any of the measured neurohumoral factors.

\section{Discussion}

Sodium retention is the cardinal manifestation of decompensated cirrhosis, but abnormalities in the handling of sodium are also evident in well compensated patients. Although there is a significant relation between abnormalities in sodium handling with severity of liver disease, the contribution of the severity of portal hypertension to this abnormality remains unknown. ${ }^{25}$ In this study, we have compared sodium handling following acute volume expansion by saline infusion in two groups of patients. Patients in group 1 had a significantly lower Pugh score and cardiac index, and significantly higher portal pressure and systemic vascular resistance compared with patients in group 2. Despite more advanced liver disease, patients in group 2 had significantly higher GFR and ERPF compared with group 1, although there was no significant difference in urinary sodium excretion. Following acute saline loading, GFR, ERPF, and sodium excretion improved significantly in both groups, suggesting that the improvement in $\mathrm{U}_{\mathrm{Na}} \mathrm{V}$ following saline infusion is the result of an 
Table 2 Changes in neurohumoral factors

\begin{tabular}{|c|c|c|c|c|c|c|c|c|c|c|}
\hline \multirow{3}{*}{$\begin{array}{l}\text { Variable } \\
\text { MAP }\end{array}$} & \multicolumn{5}{|c|}{$\operatorname{TIPSS}(n=10)$} & \multicolumn{5}{|c|}{ Preascitic cirrhotics $(n=10)$} \\
\hline & $T=0$ & $T=60$ & $T=120$ & $T=150$ & $T=180$ & $T=0$ & $T=60$ & $T=120$ & $T=150$ & $T=180$ \\
\hline & 108 & $101 \quad(4.8)$ & $101 \quad(3.7)$ & $104 \quad(2.4)$ & $105 \quad$ (3) & $112 \quad(4.3)$ & $112 \quad(7.4)$ & $102 \quad(6.6)$ & $107 \quad(5.2)$ & $106 \quad(8.1)$ \\
\hline HR & $76 \quad(4.3)$ & $78 \quad(3.1)$ & $82 \quad(2.9)$ & $81 \quad(3.9)$ & $74 \quad(2.2)$ & $84 \quad(5.1)$ & $81 \quad(3.1)$ & $86 \quad(2.1)$ & $79 \quad(3.0)$ & $77 \quad(4.5)$ \\
\hline $\mathrm{FL}_{\mathrm{Na}}$ load & $24.1(5)$ & $15.1(3)$ & $14.2(4)$ & $23.9(2)$ & $24.6(6)$ & $18.1(1) \dagger$ & $11 \quad(2.4)$ & $8.2(2.5)$ & $8.9(2.1) \dagger$ & $24.5(6)^{\star}$ \\
\hline $\mathrm{Cl}_{\mathrm{Na}}$ & $1.1(0.3)$ & $1 \quad(0.2)$ & $1.6(0.3)^{\star}$ & $2.6(0.3)^{\star}$ & $2 \quad(0.3)^{\star}$ & $1 \quad(0.2)$ & $1.6(0.6)$ & $1.8(0.2)^{\star}$ & $1.8(0.4)^{\star}$ & $2.5(0.5)^{\star}$ \\
\hline $\mathrm{FE}_{\mathrm{Na}}$ & $0.9(0.3)$ & $1.2(0.3)$ & $2.3(0.9)^{\star}$ & $2(0.7)^{\star}$ & $1.9(0.8)^{\star}$ & $1.3(0.6)$ & $2.5(1.4)^{\star}$ & $3.4(0.9)^{\star}$ & $3.1(0.9)^{\star}$ & $4 \quad(1.3)^{\star}$ \\
\hline PRA & $2.5(0.6)$ & $1.8(0.5)^{\star}$ & & & $1.9(0.6)^{\star}$ & $2.4(0.6)$ & $1.5(0.4)^{\star}$ & & & $1 \quad(0.2)^{\star}$ \\
\hline ANGII & 3 (1) & $2 \quad(0.9)$ & & & $0.8(0.6)^{\star}$ & $10 \quad(1) \dagger$ & $8.6(1) \dagger$ & & & $6.2(3)^{\star} \dagger$ \\
\hline ANP & $77.5(17)$ & $118 \quad(23)^{\star}$ & & & $90 \quad(21)$ & $64.7(20)$ & $68 \quad(23) \dagger$ & & & $52.5(19)$ \\
\hline cGMP & $3.9(0.8)$ & $4.2(1)$ & & & $4.6(1.2)$ & $5.8(2.2)$ & $6.8(2.1)$ & & & $4.1(1.3)$ \\
\hline NA & $1.5(0.4)$ & $1.6(0.5)$ & & & $1.1(0.3)$ & $1.2(0.1)$ & $1.3(0.1)$ & & & $1 \quad(0.3)$ \\
\hline ET-1 & $1.9(0.2)$ & $1.8(0.1)$ & & & $1.7(0.1)$ & $1.5(0.2) \dagger$ & $1.5(0.1) \dagger$ & & & $1.4(0.1)$ \\
\hline
\end{tabular}

Results expressed as mean (SEM).

MAP, mean arterial pressure $(\mathrm{mm} \mathrm{Hg}) ; \mathrm{HR}$, heart rate; $\mathrm{FL}_{\mathrm{Na}}$ load, filtered sodium load ( $\left.\mathrm{mmol} / \mathrm{min}\right) ; \mathrm{Cl}_{\mathrm{N} n}$, sodium clearance (ml/min); $\mathrm{FE}_{\mathrm{Na}}$, fractional excretion of sodium (\%); PRA, plasma renin activity (ng/ml/h); ANGII, angiotensin II (fmol/ml); cGMP, cyclic guanosine monophosphate (nmol/1); NA, noradrenaline (pmol/1); ET-1, endothelin-1 (fmol/1).

${ }^{\star} \mathrm{p}<0.05$ compared with baseline, $t \mathrm{p}<0.05$ between the two groups.

increase in renal blood flow and a reduction in renal vascular resistance (increased renal blood flow without any change in mean arterial pressure). Although we did not measure changes in systemic vascular resistance after saline infusion it is likely that the change in renal vascular resistance is caused by a reduction in systemic vascular resistance. ${ }^{28}$

Introduction of TIPSS in patients with refractory ascites reduces portal pressure and increases cardiac index, and urinary and fractional excretion of sodium. This improvement is caused by multiple factors related to expansion of the effective arterial blood volume and deactivation of vasopressor systems. ${ }^{21-24}$ In addition, the reduction in portal pressure gradient by the introduction of TIPSS may be envisaged to increase renal blood flow through the hepatorenal axis and therefore improve renal perfusion and sodium excretion. Lang et $a l,{ }^{29}$ in an animal model, showed an acute reduction in renal blood flow following infusion of glutamine into the portal vein. The effect of the infusion was to induce acute hepatocyte swelling and portal hypertension. This was abolished following section of the hepatic vagal fibres and renal denervation. They proposed the existence of a hepatorenal axis controlled by a reflex arc, the afferent limb of which was the hepatic vagal innervation and the efferent limb the renal sympathetic system. Stimulation of the sympathetic system produces an increase in renal vascular resistance, thereby reducing renal blood flow. ${ }^{30}$ Acute increase in portal pressure produces a significant reduction in renal blood flow and an increase in renal resistance, suggesting the existence of a signalling mechanism between the liver and the kidney. ${ }^{31}$ The higher GFR and ERPF in the TIPSS group, observed in this study, may be the result of modulation of renal blood flow through the hepatorenal reflex. The significant correlation between the portal pressure gradient and $\mathrm{U}_{\mathrm{Na}} \mathrm{V}$, both in the basal state and with acute saline loading, confirms the existence of a hepatorenal axis.

Despite the absence of ascites, the PRA and ANGII concentrations were significantly higher in the preascitic cirrhotic patients compared with healthy volunteers; this is at variance with previous data and reflects the fact that the effective arterial blood volume in these patients was low. ${ }^{32}{ }^{33}$ These differences may reflect different populations under study or a selection process. The mechanism of this activated basal renin-aldosterone-angiotensin system is not clear but may be caused by the following factors. As the preascitic cirrhotic patients in this study had established portal hypertension, the increased ANGII may reflect circulatory compensation. On the other hand, ANGII concentration was normal in patients with TIPSS, which argues for an expanded circulatory volume evidenced by significantly higher cardiac index. Studies in the isolated forearm to assess regulation of vascular tone in patients with preascitic cirrhosis has shown significant hyporesponsiveness to infusion of ANGII compared with controls. ${ }^{34}$ This observation suggests that ANGII hyporesponsiveness may be the stimulus for further activation of the renin-aldosterone-angiotensin system. The increase in $\mathrm{U}_{\mathrm{Na}} \mathrm{V}$ with concomitant reduction in PRA and ANGII following saline infusion reflects deactivation of this system with volume expansion. Further evidence for the role of ANGII in mediating sodium handling is evident from a preliminary report suggesting an improvement in urinary sodium excretion following administration of the angiotensin I receptor blocker losartan. However, the action of this drug may be modulated through its effects on reduction of the portal pressure gradient. ${ }^{35}$

The increased concentration of ET-1 shown in this study is probably the result of excessive production rather than reduced clearance. ${ }^{36} 37$ It is most likely the result of injury to the sinusoidal cells, and the higher concentration observed in patients with more advanced liver disease is consistent with previous reports. The absence of any significant change in ET-1 concentration following volume expansion suggests that the reason for this excessive production is unlikely to result from the relative hypovolaemia of cirrhosis. ${ }^{38}{ }^{39}$ Normal concentrations of noradrenaline at baseline and no significant change following volume expansion suggest that activation of the adrenergic system probably follows the development of ascites, and is consistent with the work of Wong et al who failed to show activation of the sympa- 
thetic system in preascitic cirrhosis and normal vascular responses to administration of noradrenaline in isolated forearm circulation. ${ }^{40}$ The significant increase in ANP following acute saline loading probably reflects the poorly compliant circulation following insertion of TIPSS and may have contributed in part to the enhanced urinary sodium excretion observed in the TIPSS group. cGMP measurements in this study are likely to reflect the activity of other unmeasured natriuretic factors and probably nitric oxide activity. cGMP concentration was increased in both patient groups as has been observed previously in cirrhosis. Administration of nitric oxide synthase inhibitors to cirrhotic rats was shown to improve both the haemodynamic state and also sodium handling. ${ }^{41-43}$ However, in this study the changes in renal sodium handling following acute saline loading did not seem to be related to changes in cGMP.

The results of this study suggest that the severity of portal hypertension is an important determinant of sodium retention in patients with cirrhosis and proposes the role of the hepatorenal reflex. It is likely that there are three concurrent factors which are responsible for the sodium retention of cirrhosis. Firstly, the deranged sodium handling observed in the two patient groups with activated neurohumoral systems is consistent with the original peripheral vasodilatation hypothesis which proposes the activation of vasopressor systems to counteract the effects of vasodilators on regional vascular beds as suggested by Schrier et $a l .{ }^{20}$ Secondly, severity of liver disease is an important determinant of sodium homoeostasis in cirrhosis. ${ }^{25}$ Finally, this study highlighted the role of portal pressure. The chronology of these derangements and the role of intrarenal factors in producing sodium retention of cirrhosis and ascites remains to be defined and requires longitudinal studies in patients with cirrhosis.

We gratefully acknowledge the help of Sister G Wilkie for help with the study and $\mathrm{Mr} \mathrm{N}$ Johnstone for assays of the neurohumoral factors. This study was presented in an abstract form at the meeting of the American Association for Study of Liver Diseases in Chicago, 1998 (Jalan R, Hayes PC. Renal and neurohumoral response to saline loading in pre-ascitic cirrhotics and in ascitic patients with TIPSS. Hepatology 1998;28:555A).

1 Murray JF, Dawson AM, Sherlock S. Circulatory changes in chronic liver disease. Am f Med 1958;32:358-67.

2 Kontos HA, Shapiro W, Mauck HP, et al. General and regional circulatory alterations in cirrhosis of the liver. $A m$ fMed 1964;37:526-35.

3 Kowalski HJ, Abelmann WH. The cardiac output at rest in Laennec's cirrhosis. 7 Clin Invest 1953;32:1025-33.

4 Bendtsen F, Henriksen JH, Sorensen TIA, et al. Effect of oral propranolol on circulating catecholamines in cirrhosis: oral propranolol on circulating catecholamines in cirrhosis:
relationship to severity of liver disease and splanchnic relationship to severity of liver disease an

5 Bernardi M, Trevisani F, Santini C, et al. Impairment of blood pressure control in patients with liver cirrhosis during tilting: study on adrenergic and renin-angiotensin systems. Digestion 1982;25:124-30.

6 Arroyo V, Bosch J, Mauri M, et al. Effect of angiotensin-II blockade on systemic and hepatic haemodynamics and on the renin-angiotensin-aldosterone system in cirrhosis with ascites. Eur F Clin Invest 1981;11:221-9.

7 Pariente EA, Bataille C, Bercoff E, et al. Acute effects of captopril on systemic and renal hemodynamics and on renal function in cirrhotic patients with ascites. Gastroenterology 1985;88:1255-9.

8 Ryan J, Sudhir K, Jennings G, et al. Impaired reactivity of the peripheral vasculature to pressor agents in alcoholic the peripheral vasculature to pressor agents
cirrhosis. Gastroenterology 1993;105:1167-72.

9 Martinet JP, Legault L, Cernacek P, et al. Changes in plasma endothelin-1 and big endothelin-1 induced by transjugular intrahepatic portosystemic shunts in patients with cirrhosis and refractory ascites. F Hepatol 1996;25:700-6.

10 Schroeder ET, Anderson GH, Goldman SH, et al. Effect of blockade of angiotensin II on blood pressure, renin and aldosterone in cirrhosis. Kid Intern 1976;9:511-19.

11 Floras JS, Legault L, Morali GA, et al. Increased sympathetic outflow in cirrhosis and ascites: direct evidence from intraneural recordings. Ann Intern Med 1991;114:373-80.

12 Henriksen JH, Christensen NJ, Ring-Larsen H. Noradrenaline and adrenaline concentrations in various vascular beds in patients with cirrhosis. Relation to haemodynamics. Clin Physiol 1981;1:293-304.

13 Bichet DG, Van Putten VJ, Schrier RW. Potential role of incresed sympathetic activity in impaired sodium and water excretion in cirrhosis. $N$ Engl f Med 1982;307:1552-7.

14 Bichet DG, Szatalowicz V, Chaimovitz C, et al. Role of vasopressin in abnormal water excretion in cirrhotic patients. Ann Int Med 1982;96:413-17.

15 Reznick RK, Langer B, Taylor BR, et al. Hyponatremia and arginine vasopressin secretion in patients with refractory hepatic ascites undergoing peritoneovenous shunting. Gastroenterology 1983;84:713-18.

16 Bichet DG, Groves BM, Schrier RW. Mechanisms of improvement of water and sodium excretion by immersion in decompensated cirrhotic patients. Kid Intern 1983;24: 788-94.

17 Epstein M, Weitzman RE, Preston S, et al. Relationship between plasma arginine vasopressin and renal water handling in decompensated cirrhosis. Miner Electrolyte Metab 1984;10:155-65.

18 Sherlock S, Shaldon S. The aetiology and management of ascites in patients with cirrhosis. A review. Gut 1963;4:95105.

19 Leiberman FL, Ito S, Reynolds TB. Effective plasma volume in cirrhosis with ascites: evidence that a decreased value does not account for renal sodium retention, a spontaneous reduction in glomerular filtration rate (GFR), and a fall in GFR during drug induced diuresis. $\mathcal{F}$ Clin Invest 1969;48:975.

20 Schrier RW, Arroyo V, Bernardi M, et al. Peripheral arterial vasodilatation hypothesis: a proposal for the initiation of renal sodium and water retention in cirrhosis. Hepatology $1988 ; 8: 1151-7$

21 Wong F, Sniderman K, Liu P, et al. The mechanism of the initial natriuresis after transjugular intrahepatic portosystemic shunt. Gastroenterology 1997;112:899-907.

22 Quiroga J, Sangro B, Nunez M, et al. Transjugular intrahepatic portal-systemic shunt in the treatment of refractory ascites: effect on clinical, renal, humoral, and hemodynamic parameters. Hepatology 1995;21:986-94.

23 Jalan R, Redhead DN, Thomas HW, et al. Mechanisms of changes in renal handling of sodium following transjugular intrahepatic portal systemic stent-shunt (TIPSS). Eur 7 Gastroenterol Hepatol 1996;8:1111-16.

24 Gerbes AL, Gulberg V, Waggershauser T, et al. Renal effects of transjugular intrahepatic portosystemic shunt in cirrhosis: comparison of patients with ascites, with refractory ascites, or without ascites. Hepatology 1998;28: 683-8.

25 Wong F, Massie D, Hsu P, et al. Renal response to a saline load in well-compensated alcoholic cirrhosis. Hepatology 1994;20:873-81.

26 Stanley AJ, Forrest EH, Dabos K, et al. Natriuretic effect of an adenosine-1 receptor antagonist in cirrhotic patients with ascites. Gastroenterology 1998;115:406-11.

27 Cody RJ, Haas GJ, Binkley PF, et al. Plasma endothelin correlates with the extent of pulmonary hypertension in relates with the extent of pulmonary hypertension in 1992;85:504-9.

28 Wong F, Massie D, Colman J, et al. Glomerular hyperfiltration in patients with well-compensated alcoholic cirrhosis Gastroenterology 1993;104:884-9.

29 Lang F, Tschernko E, Schulze E, et al. Hepatorenal reflex regulating kidney function. Hepatology 1991;14:590-4.

30 DiBona GF, Sawin LL. Hepatorenal baroreflex in cirrhotic rats. Am f Physiol 1995;269:G29-33.

31 Jalan R, Forrest EH, Redhead DN, et al. Reduction in renal blood flow following acute increase in the portal pressure: evidence for the existence of a hepatorenal reflex in man? Gut 1997;40:664-70.

32 Sellars L, Shore AC, Wilkinson R, et al. Sodium status and the renin-angiotensin-aldosterone system in compensated the renin-angiotensin-aldosterone system in con

33 Wong F, Sniderman K, Blendis L. The renal sympathetic and renin-angiotensin response to lower body negative pressure in well-compensated cirrhosis. Gastroenterology

34 Helmy A, Jalan R, Newby DE, et al. Role of renin angiotensin and sympathetic nervous systems in regulation of peripheral vascular tone in patients with refractory ascites [abstract]. Hepatology 1998:28:449A.

35 Girgrah N, Liu P, Blendis L, Wong F. The effect of losartan, an angiotensin II receptor antagonist, on systemic and renal hemodynamics and sodium homeostasis in cirrhosis [abstract]. Hepatology 1997;41:A233.

36 Gerbes AL, Moller S, Gulberg V, et al. Endothelin-1 and -3 plasma concentrations in patients with cirrhosis: role of splanchnic and renal passage and liver function. Hepatology 1995;21:735-9.

37 Newby DE, Jalan R, Masumori S, et al. Impaired central but stimulated humoral regulation of vascular tone in patien with cirrhosis and ascites. Cardiovasc Res 1998;38:221-8. 
38 Asbert M, Gines A, Gines P, et al. Circulating levels of endothelin in cirrhosis. Gastroenterology 1993;104:1485-

39 Salo J, Francitorra A, Follo A, et al. Increased plasma endothelin in cirrhosis. Relationship with systemic endotoxemia and response to changes in effective blood volume. F Hepatol 1995;22:389-98.

40 Wong F, Logan A, Blendis L. The effect of varying sodium intake on blood volume, forearm blood flow and vascular responsiveness to sympathetic stimulation in pre-ascitic cirrhosis. Clin Invest Med 1996;19:184-94.
41 Woitas RP, Heller J, Stoffel-Wagner B, et al. Renal functional reserve and nitric oxide in patients with compensated liver cirrhosis. Hepatology 1997;26:858-64.

42 Tajiri K, Miyakawa H, Izumi N, et al. Systemic hypotension and diuresis by $\mathrm{L}$-arginine in cirrhotic patients with ascites: role of nitric oxide. Hepatology 1995;22:1430-5.

43 Niederberger M, Gines P, Tsai P, et al. Increased aortic cyclic guanosine monophosphate concentration in experimental cirrhosis in rats: evidence for a role of nitric oxide in the pathogenesis of arterial vasodilatation in cirrhosis. Hepatology 1995;21:1625-31. 